\title{
Contingency Bases and the Problem of Sociocultural Context
}

\section{US Army Corps of Engineers ${ }_{\circledast}$}

\author{
by David A. Krooks, Lucy A. Whalley, H. Garth Anderson
}

INTRODUCTION: The United States (US) military presence during contingency operations (including combat operations, humanitarian assistance, or stability and reconstruction operations) can have a tremendous impact on the host nation and other regional actors. Recent experience has taught us that even our on-base actions can have profoundly negative consequences for the success of our missions, especially when winning the "hearts and minds" of the host nation populace is one of our goals, as it is in counterinsurgency (COIN):

Once the unit settles into the AO [area of operations], its next task is to build trusted networks. This is the true meaning of the phrase "hearts and minds," which comprises two separate components. "Hearts" means persuading people that their best interests are served by COIN success. "Minds" means convincing them that the force can protect them and that resisting it is pointless. Note that neither concerns whether people like Soldiers and Marines. Calculated self-interest, not emotion, is what counts. Over time, successful trusted networks grow like roots into the populace. They displace enemy networks, which forces enemies into the open, letting military forces seize the initiative and destroy the insurgents....Actions that help build trusted networks support the COIN effort. Actions that undermine trust or disrupt these networks - even those that provide a short-term military advantage-help the enemy. (Field Manual [FM] 3-24, paras A-26 and A-28).

Negative and Positive Effects: Among the examples of negative consequences related to contingency bases are:

- Multi-National Force-Iraq (MNF-I) Camp Alpha (September 2003 until December 2004)

- Qu'ran burning on Bagram Air Base (AB) (February 2012).

In 2009, the United Nations Educational, Scientific, and Cultural Organization (UNESCO) issued a final report on the damage done to the ancient city of Babylon by MNF-I's siting of Camp Alpha. That report summarizes the history and significance of the archeological site as follows (p 5):

Babylon is unquestionably one of the most important archaeological sites in the world. It was the capital city of two of the most famous kings of antiquity, Hammurabi (17921750 BC) who introduced one of the world's first law codes, and Nebuchadnezzar (604-562 BC) who built the Hanging Gardens of Babylon, one of the Seven Wonders of the World. Alexander the Great chose Babylon as his new capital but died before he could implement this plan.

The report further indicates (p 6) that

[o]n April 21, 2003 Babylon was occupied by military units of the Coalition Forces and on September 2nd, 2003 it became the military "Camp Alpha”. It served as such until 
December 22nd, 2004 when it was handed back to the SBAH [State Board of Antiquities and Heritage Iraq].

Although the report concedes (p 9) that MNF-I damage to the archeological site was not the first occasion on which activities in the modern era have resulted in damage, the use of Babylon as a military base also harmed the site. The damage was a result of the following sorts of activities (UNESCO, pp 13ff):

- excavation works (digging of trenches and pits)

- cutting works (horizontal cutting into a mound, removing deposits)

- scraping and leveling works (scraping and leveling of archeological areas and tells, subsequently covered with sand and gravel)

- use of removed deposits (including, in some cases, pottery fragments and baked bricks with inscriptions) to construct earthen berms

- filling of HESCO containers with soils containing pottery fragments and baked bricks

- installation (in archeological ground and on tells and walls) of barbed wire and steel stakes throughout the site.

Part of our reason for setting up Camp Alpha was to protect the site from looters (see McCarthy and Kennedy 2005), but a spokesperson for the Iraqi Ministry of Tourism is reported to have said (Anonymous 2009): "We were very disappointed when multinational forces took over these ancient sites as bases although they knew how important these sites are to Iraqis and to the entire world.”

The Iraqi perception of the United States, as presented in a Washington Post article dated 29 July 2009 after the release of the UNESCO report, was not positive (Bakri 2009). It demonstrates that the siting of contingency bases can have adverse impacts on counterinsurgency missions and the longer-term goals that those missions serve.

On 20 February 2012, US soldiers in Afghanistan charged with disposing of copies of the Qu'ran, which may have been used to transmit clandestine messages between detainees formerly held on Bagram AB, attempted to dispose of the books by burning them amid solid waste. This attempt unintentionally caused grave offense to Muslims and resulted in violent demonstrations outside the base. Said one Iraqi protester (see CBS News 2012): "They should leave Afghanistan rather than disrespecting our religion, our faith. They have to leave and if next time they disrespect our religion, we will defend our holy Quran, religion and faith until the last drop of blood has left in our body.” The British Broadcasting Service (BBC 2012) quotes another as saying "When the Americans insult us to this degree, we will join the insurgents."

In addition to the demonstrations at Bagram and elsewhere, this episode also resulted in retributive attacks against US soldiers. The week ending 2 March 2012 saw rioting across Afghanistan that resulted in the deaths of at least 29 Afghans and 6 US soldiers (see Rubin 2012). The casualties that occurred in the near term after the event at Bagram numbered over 200, and were not limited to Americans (See Elhaam and Shalizi 2012). This example demonstrates forcefully that on-base processes that are inconsistent with host nation cultural practices can have extremely deleterious effects on the success of our missions and can cost American lives. 
Not all actions related to contingency bases produce dramatic or negative consequences. In a recent telephone interview, COL Rich Staats, who served as a contingency base mayor, noted that contingency bases have economic effects that can be either temporary or longer lasting. COL Staats engaged in dialogs with local elders to ensure that, if US forces were to train local national individuals to serve as construction contractors on-base, those local nationals would be employed in the local economy once their training and on-base work were completed. This approach helped to ensure that the contingency base could continue to have a positive local effect even after the departure of US forces.

These three examples from experience highlight that among the keys to successful missions are the winning and preservation of the trust and confidence of the population of our partner nations. This trust and confidence depends crucially on relationships, and relationships cannot be built effectively without understanding the culture and the world views of our partners. This is true not only at the national and regional levels but at the local level as well. A thorough understanding of a host nation's customs, laws, and practices allows the commander to conduct business more easily, both locally and regionally. This enhances the mission and sustainment of the contingency base, and makes sociocultural understanding a de facto force multiplier.

Sociocultural Considerations: Over the past 10 years, the U.S has established hundreds of contingency bases of all sizes in Iraq, Afghanistan, other allied nations in Southwest Asia, and other theaters where the United States has strategic interests. In large measure, the Department of Defense (DoD) has until recently addressed the effects of contingency bases from the perspective of the physical environment alone, and then mainly through Annex L, Environmental Considerations, to the operations orders (OPORDs) that govern our deployments (see Mosher et al. 2008, Krooks and Kinnevan 2011). Recent ERDC research has begun to address engineered responses to the sustainability of contingency bases, especially with respect to energy, water, and waste. Here we relate that research to ongoing ERDC research in the sociocultural arena. Our objective is to outline a research program that will address the sociocultural implications of the presence of such bases for the context in which they are set.

There are currently three models for stationing our troops in theater:

1. autonomous, self-sustained operations (Special Operations)

2. living among the partner nation's population (US Marine Corps in the city of Fallujah, versus living on Camp Fallujah)

3. living separated from the partner nation's population (Camp Fallujah).

This Technical Note focuses on contingency bases that are separated from the population, although research will ultimately need to answer the question of which approach to basing is more suitable in which contexts, where suitability is measured in terms of enhanced mission success.

The missions conducted from base camps are not solely devoted to operations that are kinetic in nature. In fact, we currently see a move toward missions that are of a more preventive or proactive sort that attempt to contribute to a partner nation's stability and capacity rather than address state failure after the fact. In addition, the United States also conducts missions centered on humanitarian assistance/disaster relief (HA/DR). US missions in Haiti are an example. There are 
also stability and reconstruction missions, such as US participation in the ongoing multinational mission in the Balkans. All of these missions place US soldiers in contexts where knowledge of the sociocultural realities and mitigation of effects on the sociocultural context will improve the chances that missions will be successful.

Contingency bases that are set apart from the host nation population-the main focus of this Technical Note — can range in size from mega-bases of up to 30,000 personnel (such as Victory Base Complex in Iraq and Bagram Airfield in Afghanistan) to small combat outposts of 20-30 soldiers. The presence of US forces on contingency bases and the processes of building, operating, and closing these bases can profoundly affect the local community. We consider the range of impacts that the life cycle of a contingency base has upon the nearby community economically, culturally, and socially. We exclude from consideration the effects of the actual operations or missions "outside the wire." Likewise, we do not address bases established by Special Operations forces, such as safe houses and firebases, due to the sensitive nature of their operations.

We conclude with an outline of a research program to address the questions raised by the sociocultural impacts identified below.

BASE CAMPS-DEFINITION AND CLASSIFICATION: A base camp is defined as “...an evolving military facility that supports the military operations of a deployed unit and provides the necessary support and services for sustained operations” (see ATP 3-37.10, Base Camps [Final Draft]). Military mission is the paramount consideration in determining its capabilities and characteristics (e.g., size, duration, quality of life, level of support and services). Of these characteristics, a base camp's size and duration might be expected to have the most profound impact on nearby communities.

Size: The final draft of ATP 3-37.10 classifies base camp population and size as follows:

- extra small - 50 to $300 ; 13,000 \mathrm{~m}^{2}$

- $\quad$ small - 300 to 2,000; $180,000 \mathrm{~m}^{2}$

- medium - 2,000 to 6,$000 ; 5 \mathrm{~km}^{2}$

- large - more than 6,$000 ; 16 \mathrm{~km}^{2}$.

Duration and Level of Construction: Contingency bases can also be viewed through lenses that capture the level of permanence to which they are constructed, i.e., the relative life expectancy of the on-base structures:

- initial — intended for immediate operational use by units upon arrival for a limited time up to 6 months

- temporary - intended to increase operational efficiency for use up to 2 years, but may be used to fulfill requirements up to 5 years

- semi-permanent - a life expectancy of more than 2 years, but less than 10 years.

Again, as contingency base size and duration increase, one can reasonably expect the sociocultural implications of its presence to grow as well. 
July 2012

KEY SOCIOCULTURAL ASPECTS OF THE BASE CAMP LIFE CYCLE: Figure 1 (ATP 3-37.10 [Final Draft]) highlights the key phases of the life cycle of a contingency base. This Technical Note addresses the phases represented in the outermost circles.

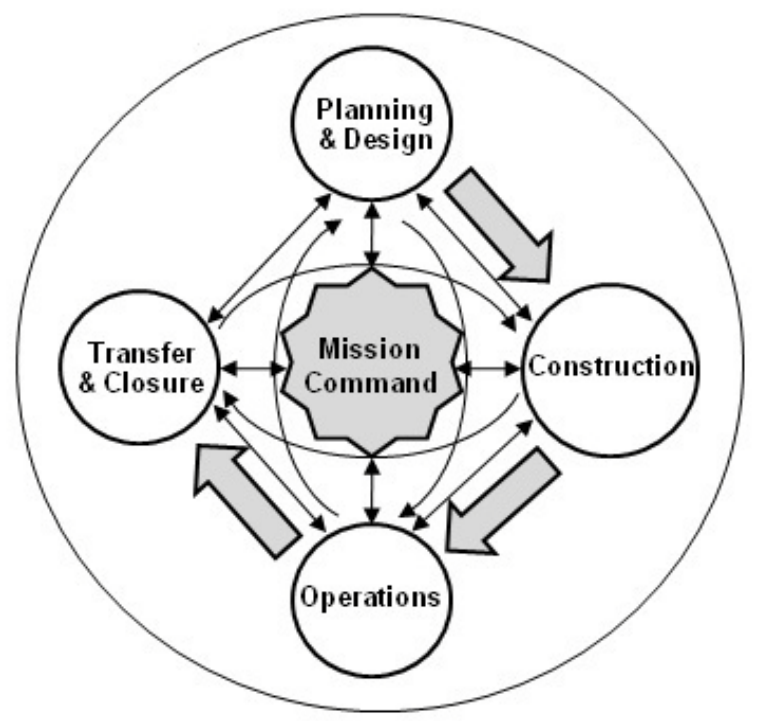

Figure 1: The Contingency Base Life Cycle

Planning and Design: Above all other criteria, planning must consider mission requirements. Other planning factors typically address themes such as resource availability, the transportation network, and local sentiment. Design issues include:

- mission

- theater guidance (e.g., The Sand Book)

- size

- expected duration of facility

- level of service of the base

- availability of construction materials

- availability of troop labor

- availability of local contractors and skilled labor

- force protection (FP) levels.

Because planning and design concerns are ongoing, almost-daily aspects of the life cycle of a contingency base, we have incorporated those considerations throughout the discussion below rather than addressing them as separate topics. Mission Command is aimed at fostering the contingency base's efficiency and effectiveness throughout its life cycle, so we do not separately address that aspect of contingency bases either. Command decisions clearly affect and shape the base's impact on the surrounding land and people; ideally, it would be the point at which those effects are considered and, to the extent possible, mitigated in advance. 
We propose questions below that can usefully be posed as the life cycle of the base unfolds. If these questions were to be raised early enough, the sociocultural implications of our presence in the physical and social landscape could be managed with a view to enhancing mission accomplishment. Therefore, the questions represent a means for assessing the sociocultural effects of the contingency base on the receiving population throughout the base's life cycle. These questions identify knowledge that should be developed and maintained throughout the contingency base life cycle in order to understand the effects of the base on the social and cultural life of the receiving nation. Addressing such questions could be the focus of a sociocultural impact assessment for contingency bases in much the same way as guiding questions orient and focus an Environmental Baseline Survey (EBS) or an Occupational and Environmental Health Site Assessment (OEHSA). Whereas an EBS assesses the impact of a contingency base on the physical environment and an OEHSA assesses the site's likely effects on soldier health, a sociocultural survey would assess the base's impact on the sociocultural environment.

These sets of questions were vetted in the course of five interviews with a former theater basing planner, base engineer, real estate specialist, and military contingency base commanders. In addition, we received comments on the questions from three subject matter experts in the areas of cultural resources, nation reconstruction, and capacity development.

Site Selection and Acquisition: ATP 3-37.10 [Final Draft] addresses site selection in great detail as part of the Planning and Design phase of the contingency base life cycle. However, the actual leasing of land appears to be a relatively minor concern in the ATP (judging from the frequency it is mentioned, at least). Because the impacts of leasing on the local sociocultural context can be significant, we break it out as a separate topic here and discuss it ahead of the construction phase.

1. How is acquisition of property handled for these various sizes of camps? What about for outposts?

2. Are there any covenants attached to leases that deal with impacts of operating a base on the property, such as dust, noise, or traffic levels; or maximum water usage; or disposal of waste or toxic or hazardous materials?

3. How is the leasing of property for construction handled in rural and urban areas of the specific country?

a. How is fair market value determined for the leasing of property?

(1) Prior Department of State transactions and those of other foreigners

(2) Real estate advertising

(3) Tax rolls

(4) Research, title searches, appraisals (for larger tracts).

b. How is ownership of property determined, thus ensuring that US funds do not support persons who oppose our interests?

4. What is the policy for reuse of existing structures on the property, e.g., buildings on former Soviet bases in Afghanistan or palaces in Baghdad's Green Zone?

5. What is the potential for conflict or unintended consequences with property owners and surrounding community members resulting from the acquisition of property for a contingency base? 
July 2012

6. Is the presence of objects of cultural heritage, of historic structures/sites, and religious structures/sites taken into account as part of the EBS?

7. Is habitat for culturally significant or protected plant or animal species a part of the environs of the contingency base?

8. Other than force of arms, what are the mechanisms for and effects of co-opting existing structures and facilities? Is it possible to mitigate those effects? Consider the following, for example:

a. The presence of a cemetery or a mosque inside the perimeter; can a sterile corridor be planned, designed, and constructed consistent with FP requirements that will still allow local nationals access to such a facility?

b. The airport at Kandahar, where the need of local nationals to go on Hajj was accommodated by the construction of facilities that allowed access to commercial aircraft.

9. What are the effects of base expansion/contraction?

a. Is expansion of the contingency base displacing agricultural uses?

b. What are the local effects of a reduction in footprint?

c. Are there other effects, such as population movement toward the base for economic opportunities or away from the base due to fear?

10. How can the base camp be used to build partner capacity?

a. Can the base camp be used to do more than simply provide jobs for local nationals?

b. How is the base camp being designed, utilized, and marketed within the context of a theater security cooperation agreement with the host nation?

Construction: Construction is typically executed using a combination of military construction units, United States Logistics Civil Augmentation Program contracts, and third-country and local contractors.

1. How is construction carried out?

a. How are construction contractors selected?

b. How is quality assurance/quality control accomplished?

c. How are construction materials acquired?

d. What is the availability of skilled labor and how is it acquired?

e. Can construction drawings and specifications be adapted to accommodate third-country and local contractors?

2. Does the construction of contingency bases affect the availability and cost of construction materials and labor? If so, how?

3. If third-country and local contractors are to be used for contingency base construction, how may differences in ways of doing business between US and foreign performers precipitate conflict or unintended consequences?

4. Will the construction of contingency bases positively or negatively affect the local economy of the construction business? If so, how?

5. If local construction methods are used, can they be adapted to meet US code and FP standards? If so, how?

6. Can the construction be managed in a way that builds partner capacity and has a positive impact on the region? 
7. How has the construction of contingency bases influenced community perception of the United States?

8. How can we most effectively design the base with a view to sustaining its utility after transfer to host nation authorities?

Operations: In this context, the word operations refers to operations and maintenance (O\&M), i.e., the functioning of the physical plant (facilities and infrastructure) and the provision of base camp services and support that fulfill the base camp's designated purpose and functional requirements. We are interested here only in those effects that flow from the presence of the base in the physical and sociocultural landscape. This Technical Note does not address the effects of offsite missions conducted by US forces. We recognize that there are both effects that might be mitigated and effects that simply cannot be mitigated without seriously compromising the security of the contingency base or the missions conducted outside its perimeter. For example, accesscontrol points are indispensible. They inevitably result in inconvenience, impatience, and frustration, but efforts can be made to manage them efficiently.

1. How does the functioning of contingency bases impact opportunities for the local labor pool?

2. How does the functioning of contingency bases provide additional services or business opportunities for the surrounding communities?

3. How do security considerations impact interaction of contingency base personnel with local leaders, national military and police partners, and local service providers?

4. How does the operation of contingency bases impact the availability of local natural resources, such as water or fuel?

5. What are the effects of our consumption of energy? Does the operation of our contingency base cause blackouts or brownouts for the local populace?

6. How does the operation of contingency bases either promote the construction of or cause the deterioration of local infrastructure, such as roads?

7. How does the operation of contingency bases pose a risk for the creation of toxic or hazardous materials or environments?

8. How has the operation of contingency bases influenced community perception of the United States?

9. Are there effects on the local aesthetic that can be mitigated? Consider the Green Zone in Baghdad. Consider barriers, perimeter fences.

10. Are access procedures culturally sensitive? (Example: females searched by females and males searched by males.)

11. Do access procedures allow for parking areas for vehicles; searching areas for humans, and support facilities for food, water, and latrines?

12. Are there sociocultural implications in the presence/use of military working dogs (MWDs) for searches of vehicles and persons? How is on-base contact with MWDs managed?

13. What law enforcement provisions are made with respect to third-country and local nationals having access to the base?

14. How are breaches of on-base rules and regulations by third-country and local nationals managed? How are on-base injuries and other health and safety issues addressed that involve local nationals with access to the base? 
July 2012

15. How is the on-base contact of third-country and local nationals with US soldiers and infrastructure controlled? How is access to sensitive facilities (e.g., hazardous materials storage, solid waste storage, power generators) regulated?

16. What are the likely effects of traffic/transport off-base on peoples' convenience, their daily schedules (e.g., shopping and worship patterns), the environment (water, waste), and movement in general?

17. Can base operations be designed to ensure that the disenfranchised elements of society are meaningfully employed so as to mitigate the growth and empowerment of violent extremist organizations?

18. What are the off-base effects of the products of base operations such as the following? Can they be mitigated?

- field sanitation

- $\mathrm{HM} / \mathrm{HW}$ storage, transportation, disposal, and safeguarding

- $\quad$ spill response and reporting

- $\quad$ petroleum, oil and lubricants (POL) storage and safeguarding

- solid waste disposal sites or waste removal

- dust generation, light pollution, noise pollution

- burn pit locations and operation

- latrine and shower facility locations

- $\quad$ wastewater treatment and disposal

- medical and infectious waste storage and disposal

- protection against disease vectors (such as rodents and insects)

- guidelines for pesticide use

- motor pool locations

- wash rack locations and operation

- drainage

- explosive ordnance disposal.

Transfer/Closure: All or part of a base camp may be closed or transferred to another service, multinational force, governmental or nongovernmental organization, or the host nation.

1. What is the potential for reuse of buildings and facilities by the above mentioned entities?

2. What are the likely effects of environmental cleanup (i.e., disposal of waste, both hazardous and nonhazardous), should it be necessary?

3. What is the risk of liability for environmental mitigation after transfer or closure?

4. What lasting effects on the economic, political, and cultural life of the surrounding communities can be observed from the operation of contingency bases?

5. How has transfer or closure of contingency bases influenced local community perception of the United States?

Summary: Across a wide range of mission types the United States uses contingency bases as support platforms from which US soldiers conduct their missions. The presence of a US contingency base has consequences that touch many sociocultural topics important to the surrounding population, as is clear from the lists of questions presented above. In the concluding section of this Technical Note we offer: 
- recommendations on policy development

- recommendations on the structure of a research program to address the constellation of sociocultural issues that the presence of a contingency base raises.

\section{RECOMMENDATIONS}

Policy Development: Over the years, the Federal government's concern about the consequences of its actions for the physical environment outside the continental United States (OCONUS) have expanded to the extent that a careful, deliberative process is now in place to ensure our respect for laws and regulations of the nations that host US forces. This evolution led to the development of the Overseas Environmental Baseline Guidance Document (OEBGD) and to the process that generates the host-nation-specific Final Governing Standards (FGS) based on it. This OEGBD-based process was developed to articulate DoD policy with respect to the physical environment as it applies to fixed, permanent installations abroad, but OCONUS contingency operations are explicitly exempted from the applicability of documents developed using this OEBGD-based process. Despite that exemption, however, Congress has articulated a concern for activities that might affect the health of US forces in contingency operations abroad (National Defense Authorization Act for Fiscal Year 2010). Section 317 of the Act includes the following mandate:

\footnotetext{
...development of regulations that prohibit the disposal of covered waste in open-air burn pits during contingency operations except in circumstances in which the Secretary [of Defense] determines that no alternative disposal method is feasible. Such regulations shall apply to contingency operations that are ongoing as of the date of the enactment of this Act, including Operation Iraqi Freedom and Operation Enduring Freedom, and to contingency operations that begin after the date of the enactment of this Act.
}

Section 317 represents the next step in the evolution of policy. In it, Congressional concern reaches directly into the conduct of contingency operations in ways that are quite specific. Section 317 goes beyond notions of environmental protection of areas that are sensitive to phases of conflict and levels of hostility. Section 317 represents a driver for policy that applies directly to what is happening while operations are actually under way. This legislative concern has since been embodied in DoD Instruction 4715.19, dated 15 February 2011, "Use of Open-Air Burn Pits in Contingency Operations."

The history of DoD policy and of engagement by the executive and legislative branches of government that we have touched on briefly above suggests an increasing willingness to engage over OCONUS contingency operations. It is not difficult to imagine that Congress, having once set a precedent for direct engagement, might engage directly again.

The reader will have noticed that the expressed legislative and policy concerns do not address the sociocultural environment. Concerns for the success of its missions on foreign soil must lead DoD to find ways to address the sociocultural environment in its policies. Absent such policies, the planners and commanders of base camps will have no drivers for obtaining the funds necessary to assess and mitigate the sociocultural effects of contingency bases. A proactive approach would necessarily involve action at a number of levels. First, the DoD must develop coherent policy that addresses the sociocultural implications of contingency bases, and it must promulgate 
that policy through the appropriate policy documents (e.g., DoD Instructions, DoD Directives). Policy that specifically addresses sociocultural considerations as they pertain to contingency bases must be developed and promulgated in a manner that will encourage rapid development of necessary doctrine, organizations, training, materiel, leadership education, personnel, and facilities (DOTMIL-PF) documents to support sociocultural assessment in contingency base camp siting, planning, and O\&M. At both the Joint and Service levels, this policy would provide the military with the needed drivers for concrete action.

An historical study by Rush (2012) highlights the importance of doctrinal reinforcement for taking into account the sociocultural effects of military actions. In her study, Rush details military precedents for protecting a foreign nation's cultural property even in times of war. However, this lesson appears to have been forgotten in recent US military experience. The article suggests that showing respect for cultural properties is critical to building relations with a population and promoting sustainable reconstruction. If US actions are to influence the population to reject violent extremist organizations and to build faith in the partner-nation government, failing to protect culture and cultural properties will be counterproductive.

Research Program: The central focus of the research proposed below is to enable the Army to identify, understand, and mitigate the sociocultural effects of the presence of US contingency bases across the life cycle of such bases.

The research program will consist of the following critical elements:

Analysis of the sociocultural effects of US military presence. The sociocultural effects of contingency bases are manifested in the political, economic, social, and cultural life of the receiving nation, as reflected in the lists of questions above. These effects are commensurate with findings on the impact of permanent US bases in foreign nations. Illustrative of the research that can be applied for understanding sociocultural effects of contingency bases is Gillem (2007), which focuses on the sociocultural impacts of the spatial presence of bases on foreign soil; Calder (2007) on the complexity of base politics involving local military facilities, host nations, and non-state actors; and Lutz (2009), which presents various perspectives from neighbors of US military bases. This body of work, in addition to the questions contained in this Technical Note, provides the basis for developing a conceptual model of the sociocultural effects of contingency bases. Research would be necessary to ground this conceptual model in the empirical reality of recent DoD experience with contingency bases and to make the research results accessible to decision makers. The research objective would be to provide methods and tools for decision makers who are planning the placement of future contingency bases to enable a more informed consideration of the effects of various courses of action on mission success.

Develop a methodology and tools for use in assessing sociocultural effects. This research would necessarily involve the development of metrics for such effects. The assessment tool could then be incorporated into the existing process for conducting an EBS or OEHSA in much the same way that a social impact assessment is conducted as part of a National Environmental Policy Act (NEPA)-type environmental impact assessment. 
Develop effects mitigation/enhancement strategies that support both contingency base operations and sustainable outcomes of base camp transfer/closure. Research could include the development of a methodology for modeling the strategic effects of contingency base, and this could be used for the development of a forecasting tool for planning the location, construction, operation, and transfer/closure of contingency bases in support of the US mission. Failure to mitigate negative effects of the operation of contingency bases over their life cycles will impact the success of the US/coalition mission. In addition, if the transfer/closure of contingency bases does not support the development of the capacity of the host-nation government and the local population, then accomplishing the long-term goals of the US/coalition mission will be jeopardized.

\section{Develop methods and tools for in-situ monitoring and evaluation of the effects of contingency} base operations. This is both analogous to environmental compliance monitoring and, in addition, relevant (as atmospherics) to Civil Affairs operators. The results of such research on in-situ monitoring would support the integration of sociocultural effects into the on-site planning for the base and its O\&M. In addition, the effects could be connected to the measures of effectiveness for meeting the overall US mission goals so that the strategic consequences of local actions are considered in higher-echelon planning processes.

Conclusion: It will be critical for the US military to understand how to employ the life-cycle operation of contingency bases in support of the mission in ways that deny insurgents and violent extremist organizations room to maneuver and build the capacity of partner nations. Research should consider whether the current US model of separating the military from the community is the most effective model for gaining the trust and confidence of the community. Current ERDCCERL research on sustainability issues for forward operating bases would complement these proposed research efforts.

\section{REFERENCES}

Anonymous. 2009. “US Troops Accused of Damaging Babylon’s Ancient Wonder.” CNN.com, 31 July 2009. (http://articles.cnn.com/2009-07-31/world/iraq.babylon.damage_1_babylon-site-euphrates-river-ishtargate?_s=PM:WORLD; last accessed 4 April 2012).

Bakri, Nada. 2009. “Six Years After US Troops' Arrival in Iraq, Ruins of Babylon Await Restoration.” The Washington Post. Wednesday, July 29, 2009. (http://www.washingtonpost.com/wpdyn/content/article/2009/07/28/AR2009072802835.html; last accessed 4 April 2012).

BBC News. 2012. “Six dead in Afghanistan Koran burning protests.” 22 February 2012. (http://www.bbc.co.uk/news/world-asia-17123464; last accessed 4 April 2012).

Calder, Kent E. 2007. Embattled Garrisons: Comparative Base Politics and American Globalism. Princeton: Princeton University Press.

CBS News. 2012. “Quran burning angers Afghans; US vows probe.” 21 February 2012. (http://www.cbsnews.com/8301-202_162-57381495/quran-burning-angers-afghans-u.s-vows-probe/; last accessed 4 April 2012).

Elhaam, Fraidoon and Hamid Shalizi. 2012. "Seven US soldiers wounded after Afghan NATO base attacked.” 26 February 2012. (http://www.reuters.com/article/2012/02/26/us-afghanistan-shooting-suspectidUSL4E8DQ03N20120226; last accessed 4 April 2012).

Gillem, Mark L. 2007. America Town: Building the Outposts of Empire. Minneapolis: University of Minnesota Press. 
July 2012

Headquarters, Department of the Army (HQDA). 2006. Counterinsurgency. FM 3-24. Washington, DC: HQDA.

Headquarters, Department of the Army (HQDA). 2011. Base Camps. Army Techniques Publication (ATP) 3-37.10. (Final Draft) Washington, DC: HQDA.

Hohn, Maria and Moon Seungsook, eds. 2010. Over There: Living with the US Military Empire from World War Two to the Present. Durham: Duke University Press.

International Coordination Committee for the Safeguarding of the Cultural Heritage of Iraq, Sub-Committee on Babylon. 2009. Final Report on Damage Assessments in Babylon. (Report Number CLT/EO/CIP/2009/RP/114). Paris: United Nations Educational, Scientific, and Cultural Organization. (http://unesdoc.unesco.org/images/0018/001831/183134e.pdf; last accessed 4 April 2012).

Krooks, David A. and Kurt Kinnevan. 2011. Analysis of Policy and Guidance Regarding Sustainability and Environmental Considerations in Overseas Contingency Operations in the Joint, Interagency, Intergovernmental, and Multinational (JIIM) Environment. ERDC/CERL SR-11-Draft. Champaign: ERDC/CERL. (Prepared for the Army Environmental Policy Institute, Arlington, VA)

Lutz, Catherine, ed. 2009. The Bases of Empire: The Global Struggle against US Military Posts. New York: New York University Press.

McCarthy, Rory and Maev Kennedy. 2005. "Babylon Wrecked by War.” The Guardian. 15 January 2005. (http://www.guardian.co.uk/world/2005/jan/15/iraq.arts1; last accessed 4 April 2012).

Mosher, David E. et al. 2008. Green Warriors: Army Environmental Considerations for Contingency Operations from Planning through Post-Conflict. Santa Monica, Arlington, Pittsburgh: RAND Corporation.

Rubin, Alissa J. 2012. “Chain of Avoidable Errors Cited in Koran Burning.” The New York Times. 2 March 2012. (http://www.nytimes.com/2012/03/03/world/asia/5-soldiers-are-said-to-face-punishment-in-koran-burningin-afghanistan.html; last accessed 4 April 2012).

Rush, Laurie W. 2012. “Cultural Property Protection as a Force Multiplier in Stability Operations.” Military Review. March-April 2012, pp 36-43.

US Army Engineer School. 2009. Baseline Survey and Occupational and Environmental Health Site Assessment Handbook: Contingency Operations (Overseas). (Dated October 2009). Ft Leonard Wood, MO: USAES.

US Central Command. 2009. Regulation 415-1, Construction - Construction and Base Camp Development in the USCENTCOM Area of Responsibility. "The Sand Book." (Dated 15 April 2009). MacDill Air Force Base, FL: US Central Command.

US Department of Defense. 2011. DoD Instruction 4715.19, 15 February 2011, “Use of Open-Air Burn Pits in Contingency Operations.”

US Secretary of Defense. January 2012. Sustaining US Global Leadership: Priorities for the $21^{\text {st }}$ Century.

ADDITIONAL INFORMATION: This work was performed under the supervision of the Business Processes Branch of the Installations Division, US Army Engineer Research and Development Center, Construction Engineering Research Laboratory (ERDC-CERL). The Technical Note was prepared for the Center for the Advancement of Sustainability Innovations (CASI), William D. Goran, Director. This document should be cited as:

Krooks, David A., Lucy A. Whalley, and H. Garth Anderson. 2012. Contingency Bases and the Problem of Sociocultural Context. ERDC/CERL TN-12-2. Champaign, IL: US Army Engineer Research and Development Center, Construction Engineering Research Laboratory (ERDC-CERL).

DISTRIBUTION STATEMENT: Approved for public release; distribution is unlimited. 


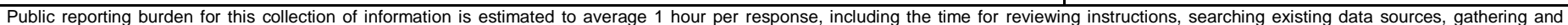

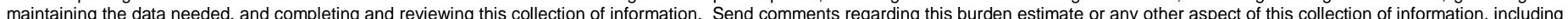

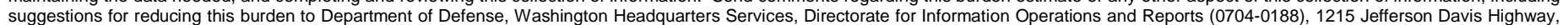

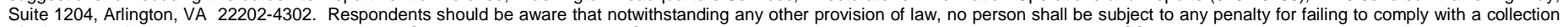
of information if it does not display a currently valid OMB control number. PLEASE DO NOT RETURN YOUR FORM TO THE ABOVE ADDRESS.

\begin{tabular}{l|l} 
1. REPORT DATE (DD-MM-YYYY) & 2. REPORT TYPE
\end{tabular}

July 2012

Final

4. TITLE AND SUBTITLE

Contingency Bases and the Problem of Sociocultural Context

5a. CONTRACT NUMBER

5b. GRANT NUMBER

5c. PROGRAM ELEMENT NUMBER

6. AUTHOR(S)

David A. Krooks, Lucy A. Whalley, and H. Garth Anderson

5d. PROJECT NUMBER

5e. TASK NUMBER

5f. WORK UNIT NUMBER

7. PERFORMING ORGANIZATION NAME(S) AND ADDRESS(ES)

US Army Engineer Research and Development Center

Construction Engineering Research Laboratory

P.O. Box 9005

Champaign, IL 61826-9005

8. PERFORMING ORGANIZATION REPORT NUMBER

ERDC/CERL TN-12-2

\section{SPONSORING I MONITORING AGENCY NAME(S) AND ADDRESS(ES)}

Headquarters, US Army Corps of Engineers

441 G Street NW

Washington, DC 20314-1000

10. SPONSOR/MONITOR'S ACRONYM(S)

11. SPONSOR/MONITOR'S REPORT NUMBER(S)

\section{DISTRIBUTION / AVAILABILITY STATEMENT}

Approved for public release; distribution is unlimited.

\section{SUPPLEMENTARY NOTES}

\section{ABSTRACT}

United States (US) military presence during contingency operations can have a large impact on the host nation and other regional actors. Recent experience has shown that even on-base actions can have profoundly negative consequences for the success of US missions. One key to successful missions is to win and preserve the trust and confidence of the affected population. A thorough understanding of a host nation's customs, laws, and practices enables the commander to execute the mission with fewer obstacles, both locally and regionally.

This Technical Note discusses the issue of how to approach setting up and operating contingency bases within different sociocultural contexts. The authors consider the range of impacts that a contingency base life cycle may have upon the nearby community economically, culturally, and socially. Detailed criteria are presented for consideration in the acquisition, construction, and operation of contingency bases, and the outline of a research program is proposed to address both documented and prospective negative sociocultural impacts.

\section{SUBJECT TERMS}

contingency operations, military installations, forward operating bases, sociocultural contexts, society, culture, economy, impacts

\section{SECURITY CLASSIFICATION OF:}

\section{a. REPORT}

Unclassified

\section{b. ABSTRACT}

Unclassified c. THIS PAGE

Unclassified
17. LIMITATION OF ABSTRACT

\section{NUMBER OF PAGES}

13 19a. NAME OF RESPONSIBLE PERSON

19b. TELEPHONE NUMBER (include area code) 